\title{
Physicochemical Characterization of Febuxostat Microcomplexes with Parent and Modified Cyclodextrins
}

\author{
Sayee V. Aher ${ }^{1}$ and Yogesh V. Pore ${ }^{2}$ \\ ${ }^{1}$ Department of Pharmaceutical Chemistry, Government College of Pharmacy, Karad \\ Maharashtra 415 124, India \\ ${ }^{2}$ Department of Pharmaceutical Chemistry, Government College of Pharmacy, Ratnagiri \\ Maharashtra 415 612, India
}

(Received: 30 January, 2018; Accepted: 15 March, 2018; Published (web): 10 June, 2018)

\begin{abstract}
Febuxostat, a BCS class II antigout drug was complexed with $\beta$-cyclodextrin ( $\beta C D)$, hydroxypropyl- $\beta$ cyclodextrin (HP $\beta C D$ ) and / or methyl- $\beta$-cyclodextrin $(\mathrm{M} \beta C D)$, to improve its physicochemical properties. Earlier phase solubility and thermodynamic investigations in acetate buffer $(\mathrm{pH} 4.5)$ illustrated $\mathrm{A}_{\mathrm{L}}$ (linear) type of solubility curve and enthalpy driven complexation process, respectively. The association constant and complexation efficiency of modified cyclodextrins (CDs) were significantly higher than that of parent cyclodextrin (CD). The microcomplexes prepared by spray drying process were examined for their spectral, diffractometric, thermal, particle size, saturation solubility, $\log P$ and dissolution properties. The physicochemical properties of pure drug were improved upon complexation with CDs. However, modified CDs produced amorphous micro-complexes contributing for their better performance as compared to parent $\mathrm{CD}$.
\end{abstract}

Key words: Febuxostat; cyclodextrins; micro-complexes; characterization; thermodynamic; phase solubility.

\section{INTRODUCTION}

Cyclodextrins (CDs) are cyclic oligosaccharides containing internal hydrophobic central cavity and external hydrophilic surface produced from starch which contain six ( $\alpha$-CDs), seven ( $\beta$-CDs), eight ( $\beta$ CDs) glycopyranose units linked by $\alpha-1,4$ glucosidic bonds. The $\beta$-form is widely accessible and mostly preferred cyclodextrin with 6-7 $\AA$ internal cavity size. ${ }^{1,2}$ The inclusion phenomena of drug (guest) into the cyclodextrin (host) is the most extensively used and industrially applicable technique exploited to enhance the physicochemical properties of the guest. ${ }^{3,4} \mathrm{CDs}$ have been promisingly established to be the modifiable and flexible carriers in the pharmaceutical research. On the contrary, the natural

Correspondence to : Yogesh V. Pore

Tel: +91-02352-221201

Email: dryogeshpore@rediffmail.com

Dhaka Univ. J. Pharm. Sci. 17(1): 51-63, 2018 (June) parent $\beta$-cyclodextrin $(\beta C D)$ have constrained the solubility and the complexation with the hydrophobic active moieties. ${ }^{1}$ Further, modification in the parent CDs have widen the scope and use of modified CDs towards improving the properties of active pharmaceutical ingredients (APIs) due to their advantages such as high efficiencies, amorphous nature ${ }^{5}$, low cost and low toxicity. ${ }^{6}$

Febuxostat (FBX) (Figure 1) is a thiazole derivative, non-purine-selective inhibitor of xanthine oxidase (XO) enzyme that converts oxypurines like hypoxanthine and xanthine, into uric acid. ${ }^{7}$ It is orally used in treatment of gout. The essential structural aspect of FBX is the presence of lipophilic functionality that promotes its absorption upon oral administration. Nonethlessly, FBX exists in crystalline state and has poor water solubility and dissolution in gastrointestinal tract. Therefore, these properties of FBX are bound to limit its use resulting 
in poor therapeutic window. Hence FBX was selected for cyclodextrin complexation. Very few experiments have been performed on FBX cyclodextrin complexation for its solubility and dissolution improvement. ${ }^{8,9} \quad$ However, complexation with methyl- $\beta$-cyclodextrin $(\mathrm{M} \beta \mathrm{CD}$ ) has not been reported yet.

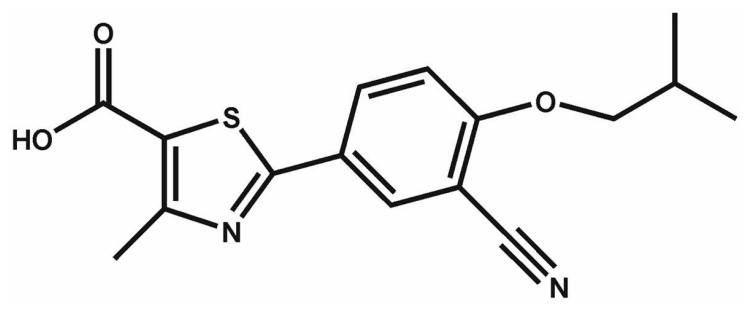

Figure 1. Chemical srtructure of febuxostat (FBX).

The objectives of the present work were to investigate the efficiencies and physicochemical properties of FBX with parent and modified cyclodextrins. Firstly, the stiochiometry of complexation along with thermodynamic parameters for the complexation phenomena was assessed by phase solubility studies. The spray dried complexes were characterized by thermal, diffractometric particle size analysis, fourier transform infrared spectroscopy (FTIR), scanning electron microscopy (SEM), saturation solubility, partition coefficient determination $(\log P)$ and drug content uniformity. The dissolution profile of pure drug and complexes were further assessed in phosphate buffer $\mathrm{pH}$ 7.4.

\section{MATERIAL AND METHODS}

Materials. FBX was provided by INDOCO Remedies Ltd.,Waluj, India as a gift sample. $\beta C D$ and hydroxypropyl- $\beta$-cyclodextrin (HP $\beta C D)$ were supplied by Gangwal Chemicals, Mumbai, India. M $\beta C D$ was purchased from TCI Chemicals, Mumbai, India. The reagents used were all of pharmaceutical and analytical grade. All materials were used as received without further purification .

Phase solubility studies and thermodynamic investigations. The most widely used approach to study inclusion complexation is the phase solubility method described by Higuchi and Connors, which examines the effect of a solubilizer (CD or ligand) on the drug being solubilized (substrate). ${ }^{10}$ For phase solubility studies, an excess amount of FBX was added to $10 \mathrm{~mL}$ of acetate buffer ( $\mathrm{pH} 4.5)$ containing $0-5 \mathrm{mM}$ of $\beta C D$ or HP $\beta C D$ or M $\beta C D$ solutions and transferred to $25 \mathrm{~mL}$ of screw cap glass tubes. The suspensions were sealed and equilibrated in a shaking incubator at $150 \mathrm{rpm}$ for $48 \mathrm{~h}$ at 298, 303, $310 \pm 2 \mathrm{~K}$ temperatures. After equilibrium was achieved, aliquots of $2 \mathrm{ml}$ were withdrawn and filtered immediately using $0.45 \mu \mathrm{m}$ membrane filter. The filtered samples were diluted suitably with distilled water and assayed for FBX by measuring absorbance at $313.5 \mathrm{~nm}$ against blank by UV-Visible spectrophotometer (Shimadzu 1800, Japan). The stability constant $(K \mathrm{~s})$ was calculated from phase solubility diagrams assuming the $1: 1$ stoichiometry, according to following equation. ${ }^{5}$

$$
K \mathrm{~s}=\quad \text { Slope } / S_{0} \text { (1-Slope) }
$$

$S_{0}$ is the solubility of FBX in absence of CDs.

Complexation efficiency

$(\mathrm{CE})=S_{\mathrm{o}} \mathrm{K}_{1: 1}=$ Slope/ (1-Slope)

For the assessment of thermodynamic parameters from phase solubility curves, an integrated form of the Van't Hoff equation (as shown below) was employed for the calculations of the enthalpy $(\Delta \mathrm{H})$ and of entropy $(\Delta S)$, corresponding to the changes observed in stability constants with temperatures ${ }^{5}$

$$
\text { In } \mathrm{K}=-\Delta \mathrm{H} / \mathrm{RT}+\Delta \mathrm{S} / \mathrm{R}
$$

$\Delta \mathrm{H}$ and $\Delta \mathrm{S}$ are the enthalpy and entropy of the complex respectively, $\mathrm{R}$ is the gas constant, and $\mathrm{T}$ is temperature in Kelvin.

An indication of process of transfer of FBX from pure water to buffer solution of $\beta C D, H P \beta C D$, $\mathrm{M} \beta \mathrm{CD}$ was obtained from the values of Gibbs free energy of transfer $\left(\Delta \mathrm{G}_{\mathrm{tr}}{ }^{\circ}\right)$ and it was calculated using the following equation:

$$
\Delta \mathrm{Gtr}^{0}=-2.303 \mathrm{RT} \log \left(\mathrm{Sc} / S_{0}\right)
$$

Where, $S \mathrm{c} / S_{0}$ is the ratio of molar solubility of FBX in buffer solution to that in buffer solution in absence of CDs. 
Preparation of solid systems by spray drying. For the preparation of binary system, equimolar quantities of FBX and CDs were transferred into conical flask containing $200 \mathrm{ml}$ of methanolic acetate buffer ( $\mathrm{pH} 4.5)$ and sonicated for $10 \mathrm{~min}$. The mixture was stirred for $96 \mathrm{~h}$ at a room temperature $\left(25 \pm 2^{\circ} \mathrm{C}\right)$ on $150 \mathrm{rpm}$ by using a magnetic stirrer. The solution was filtered immediately using $0.45 \mu \mathrm{m}$ membrane filter to separate uncomplexed drug. The resultant solution was spray dried using Lab spray dryer (SPD-D-111 Techno Search Instruments, Thane, India) under following set of conditions: Inlet temp, $65^{\circ} \mathrm{C}$, outlet temp $45^{\circ} \mathrm{C}$, cool temp $20^{\circ} \mathrm{C}$, aspirator speed $40 \mathrm{mbr}$, feed rate $8 \mathrm{~mL} / \mathrm{min}$. The spray dried powder was stored in desiccators, to prevent it from moisture absorption.

Particle size and zeta potential analysis. The micro-complexes were characterized for particle size using a Horiba nanoparticle size analyzer (HORIBA SZ-100, Japan). The particle size distribution is given by $d(0.9), d(0.5)$ and $d(0.1)$ which is the particle size diameters determined at the $90^{\text {th }}, 50^{\text {th }}$, and the $10^{\text {th }}$ percentile of particle undersized, respectively.

X-ray powder diffractometry (XRPD). The XRPD patterns of FBX, $\beta C D, H P \beta-C D, M \beta-C D$ and all complexes were recorded by using $\mathrm{X}$-ray diffractometer (BRUKER-D2 PHA-SER, Germany) with tube anode $\mathrm{Cu}$ over the interval $10-80^{\circ} / 2^{\circ}$. The operational data were as follows: Generator tension (voltage) $40 \mathrm{kV}$, Generator current $30 \mathrm{~mA}$, and scanning speed $2 \%$ min.

Differential scanning calorimetry (DSC). Thermal analysis of all samples were performed on DSC analyzer (TA Instruments, SDT Q600,USA). A sample $(5 \mathrm{mg}$ ) was sealed in an aluminium pan and heated under a nitrogen atmosphere at a heating rate of $10^{\circ} \mathrm{C} / \mathrm{min}$ over the temperature range of $30-300^{\circ} \mathrm{C}$.

Fourier transform infrared spectroscopy (IR). IR (Bruker, Germany) was used in attenuated total reflectance (ATIR) model for collecting the IR spectra of the samples. The spectra of the samples were collected over the range of $4000-600 \mathrm{~cm}^{-1}$ in 24 scans, with a resolution of $4 \mathrm{~cm}^{-1}$ for each sample by using opus software.
Scanning electron microscopy (SEM). All samples were directly mounted on aluminium stub and coated with a thin gold-ion layer by sputter coated unit. The surface morphology was examined with a scanning electron microscopy (SEM-JEOL Instruments, JSM-6360, Japan.) operated at an acceleration voltage of $20 \mathrm{kV}$ and obtained micrographs were examined at x $500, \mathrm{x} 1,000, \mathrm{x} 2,000$ magnifications.

Percentage drug content study. Drug content was examined by dissolving prepared binary complexes equivalent to $5 \mathrm{mg}$ drug in methanol. The volume was adjusted with distilled water. The solution was filtered through Whatmann filter paper no. 41 , suitably diluted and absorbance was measured at $314.5 \mathrm{~nm}$ using a UV spectrophotometer (Shimadzu 1800, Japan).

Saturation solubility studies. The saturation solubility studies were carried out in triplicate manner, by adding an excess amount of FBX and / or complexes to $10 \mathrm{ml}$ of distilled water in solubility tubes and shaken on rotary shaker at room temperature $\left(25 \pm 2^{\circ} \mathrm{C}\right)$ on $150 \mathrm{rpm}$ for $24 \mathrm{~h}$. After reaching equilibrium, aliquots of the solution withdrawn and filtered with Whatman filter paper no. 41, suitably diluted and absorbance was measured at $314.5 \mathrm{~nm}$ by UV-spectrophotometer (Shimadzu 1800, Japan) and the results were statistically analyzed using appropriate method.

In vitro drug release. The dissolution studies of FBX alone and binary systems were carried out in triplicate manner in dissolution apparatus (ELECTROLAB-TST-06L/LX, New Mumbai, India), using the paddle method, according to USP type II. Samples were added in dissolution vessel containing $900 \mathrm{~mL}$ of phosphate buffer ( $\mathrm{pH} 7.4$ ), maintained previously at $37 \pm 0.5^{\circ} \mathrm{C}$ at $100 \mathrm{rpm}$ according to US FDA guidelines. $80 \mathrm{mg}$ of pure drug or its equivalent amount of prepared binary inclusion complexes were added to $900 \mathrm{~mL}$ of phosphate buffer (pH 7.4). $5 \mathrm{ml}$ of sample was withdrawn at time intervals of $5,10,15,30,45,60$ and $90 \mathrm{~min}$. The volume of dissolution medium was adjusted to $900 \mathrm{ml}$ by replacing each $5 \mathrm{~mL}$ aliquot withdrawn 
with $5 \mathrm{ml}$ of fresh phosphate buffer ( $\mathrm{pH}$ 7.4). The solution was filtered through $0.45 \mu \mathrm{m}$ Whatman filter paper 41, suitably diluted and concentrations of FBX in the samples were determined spectrophotometrically at $314 \mathrm{~nm}$ (Shimadzu 1800, Japan).

Determination of partition coefficient $(\log P)$. For the determination partition coefficient, $10 \mathrm{ml}$ each of octanol and water were added in glass tubes and allowed to stand overnight for $24 \mathrm{hrs}$ at room temperature. The excess amount (equivalent to 25 $\mathrm{mg}$ ) of pure drug and /or complexes were added to the tubes and shaken on an incubator shaker (REMICIS 24 plus Incubator shaker, Mumbai, India) for 24 hrs at $25^{\circ} \mathrm{C}$. The mixtures were transferred to separating funnel and allowed to stand about $6 \mathrm{~h}$ for equilibration. Aqueous and organic phase was separated and concentration of drug in aqueous phase was detremined spectrophotometrically (Shimadzu 1800, Japan) at $314.3 \mathrm{~nm}$. The partition coefficient was calculated by following formula,
Partition coefficient $(\log \mathrm{P})=\left(\log \mathrm{C}_{\text {octanol }} / \mathrm{C}\right.$ water)

Where $\mathrm{C}$ is the concentration of the drug in octanol and/or water phase. ${ }^{5}$

\section{RESULTS AND DISCUSSION}

Phase solubility and thermodynamic investigations. The phase solubility curve of FBX in buffer CDs solutions at 298, 303, $310 \pm 2 \mathrm{~K}$ are shown in figure 2 . All phase solubility parameters investigated are shown in table 1 . The solubility of FBX increased linearly ( $A_{L}$-type) as a function of CDs concentration, illustrating formation of soluble complexes in all systems. ${ }^{11}$ The slopes of all phase solubility diagrams found to be less than unity estimating 1:1 stoichiometry in all cases. ${ }^{10}$ The $K$ s and $\mathrm{CE}$ of $\beta C D$ were significantly upgraded in case of $\mathrm{HP} \beta C D$ and $M \beta C D$ justifying positive effect of modified CDs towards solubility enhancement of FBX.

Table 1. Phase solubility data of binary complexes of FBX with $\beta C D$, HPßCD and M $\beta C D$.

\begin{tabular}{|c|c|c|c|c|c|c|}
\hline $\begin{array}{l}\text { Complex/ } \\
\text { Parameter }\end{array}$ & $\mathrm{T}(\mathrm{K})$ & $S_{\mathrm{o}}$ & Slope & $\mathrm{R}^{2}$ & $K \mathrm{~s}\left(\mathrm{M}^{-1}\right)$ & C.E. \\
\hline \multirow[t]{3}{*}{$F B X-\beta C D$} & 298 & 0.00004241 & 0.10548 & 0.995 & 2867 & 0.11 \\
\hline & 303 & 0.00007631 & 0.09189 & 0.997 & 1446 & 0.10 \\
\hline & 310 & 0.0001607 & 0.11212 & 0.993 & 790 & 0.13 \\
\hline \multirow[t]{3}{*}{ FBX-HР $\beta C D$} & 298 & 0.00004241 & 0.13998 & 0.998 & $3192^{a}$ & $0.16^{b}$ \\
\hline & 303 & 0.00007631 & 0.15707 & 0.995 & $2662^{a}$ & $0.19^{b}$ \\
\hline & 310 & 0.0001607 & 0.18705 & 0.996 & $1588^{a}$ & $0.23^{b}$ \\
\hline \multirow[t]{3}{*}{ FBX-M $\beta C D$} & 298 & 0.00004241 & 0.32997 & 0.999 & $11869^{a}$ & $0.49^{b}$ \\
\hline & 303 & 0.00007631 & 0.31245 & 0.997 & $9888^{a}$ & $0.45^{b}$ \\
\hline & 310 & 0.0001607 & 0.49267 & 0.998 & $5019^{a}$ & $0.97^{b}$ \\
\hline
\end{tabular}

Binary complexes: FBX- $\beta C D$, FBX-HP $\beta C D$, FBX-M $\beta C D$; FBX: Febuxostat; $\beta C D$ : $\beta$-cyclodextrin; HP $\beta C D$ : Hydroxy propyl $\beta$ cyclodextrin; M $\beta C D$ : Methyl $\beta$-cyclodextrin; $S_{0}$ : solubility of FBX in absence of $\beta C D, H P \beta C D, M \beta C D ; R^{2}$ : regression coefficient of phase solubility plot; $K \mathrm{~s}\left(\mathrm{M}^{-1}\right)$ : association constant of complexes; CE: complexation efficiency; ${ }^{a}$ : significant difference compared to FBX- $\beta \mathrm{CD}$ $(p<0.001)$ i.e. significant; ${ }^{b}$ : significant difference compared to $\operatorname{FBX}-\beta C D(p<0.001)$ i.e. significant.

The phase solubility data accomplished at different temperatures gave subsidiary particulars like thermodynamic specifications associated with formation of inclusion complexes as in table 2. The Van't Hoffs plot (Figure 3) exemplified the linear function between $K \mathrm{~s}$ and the inverse of absolute temperatures $(1 / T)$. The values of enthalpy $(\Delta \mathrm{H})$ comprehending to all the systems were found to be negative, revealing the complexation process to be enthalpy driven exothermic process. The more negative values of the entropy $(\Delta \mathrm{S})$ indicated the high orderness of complexes in case of all the systems. 
The complexation process being exothermic and decrease in the entropy of the system demonstrating the spontaneity of complex formation towards the lower temperature. An indication of process of transfer of FBX from buffer solution to aqueous buffer solution of CDs was procured from the values
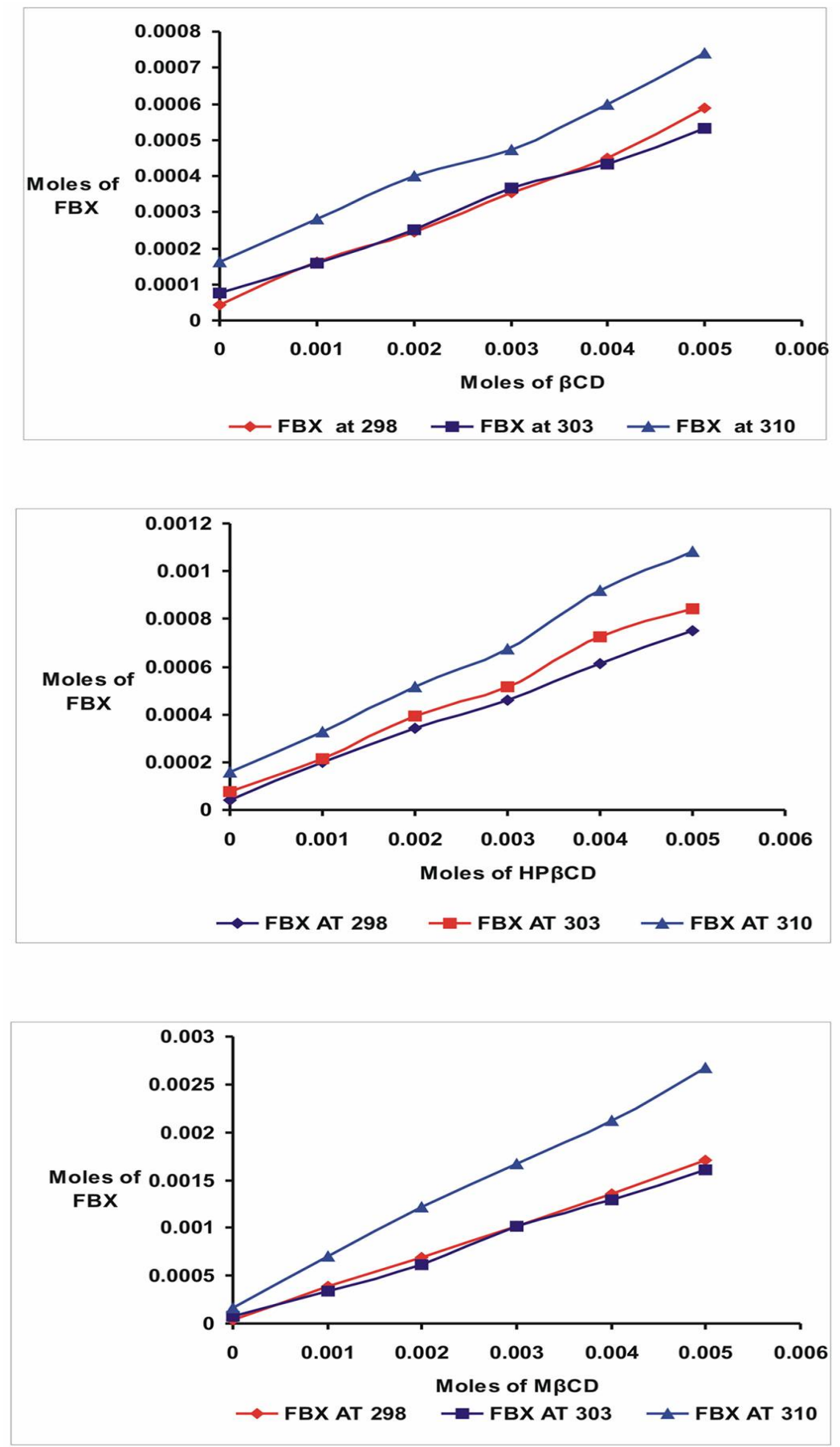

Figure 2. Phase solubility diagram of FBX: $\beta C D$, FBX:HP $\beta C D$, FBX:M $\beta C D$ inclusion complexes at $298,303,310 \pm 2$ K in acetate buffer $\mathrm{pH}$ 4.5. FBX: Febuxostat; $\beta C D$ : $\beta$-cyclodextrin; HP $\beta C D$ : Hydroxy propyl $\beta$-cyclodextrin; M $\beta C D$ : Methyl $\beta$-cyclodextrin. 
Table 2. Thermodynamic specifications involved in inclusion phenomena of FBX with cyclodextrins.

\begin{tabular}{llll}
\hline Complex /Thermodynamic Parameter & $\Delta \mathrm{H}(\mathrm{kJ} / \mathrm{mol})$ & $\Delta \mathrm{S}(\mathrm{J} / \mathrm{mol} / \mathrm{K})$ & $\Delta \mathrm{G}(\mathrm{kJ} / \mathrm{mol})$ \\
\hline FBX- $\beta C D$ & -81.60 & -208.01 & -19.62 \\
FBX-HP $\beta C D$ & -45.39 & -84.81 & -20.11 \\
FBX-M $\beta C D$ & -57.13 & -113.06 & -23.42 \\
\hline
\end{tabular}

Binary complexes: FBX- $\beta C D$, FBX-HP $\beta C D$, FBX-M $\beta C D$; FBX: Febuxostat; $\beta C D$ : $\beta$-cyclodextrin; HP $\beta C D$ : Hydroxy propyl $\beta$ cyclodextrin; $\mathrm{M} \beta C D$ : Methyl $\beta$-cyclodextrin; $\Delta \mathrm{H}$ : enthalpy; $\Delta \mathrm{S}$ : entropy; $\Delta \mathrm{G}$ : Gibb's free energy

Table 3. Particle size, zeta potential and polydispersity index of microcomplexes of FBX with cyclodextrins.

\begin{tabular}{|c|c|c|c|}
\hline Complex/ Parameter & Particle size $(\mu \mathrm{m})$ & Zeta potential $( \pm \mathrm{mV})$ & Polydispersity index (PI) \\
\hline FBX & 2.7333 & -41.3 & 3.424 \\
\hline $\mathrm{FBX}-\beta C D$ & 1.0889 & -25.6 & 0.449 \\
\hline FBX-HPßCD & 0.1901 & -41.7 & 2.716 \\
\hline FBX-MßCD & 0.8227 & -28.8 & 0.528 \\
\hline
\end{tabular}

Binary complexes: FBX- $\beta C D$, FBX-HP $\beta D$, FBX-M $\beta C D$; FBX: Febuxostat; $\beta C D$ : $\beta$-cyclodextrin; HP $\beta C D$ : Hydroxy propyl $\beta$-cyclodextrin; M $\beta C D$ : Methyl $\beta$-cyclodextrin

of gibbs free energy change. For the concentration of $\beta C D, H P \beta C D, M \beta C D, 0.001,0.002,0.003,0.004$, $0.005 \mathrm{M}$, the values of $\Delta \mathrm{Gtr}^{\circ}(\mathrm{kJ} / \mathrm{mol})$ in buffer solution of $\beta C D$ were found to be, $-279.84,-365.41$, $-441.27,-476.45,-546.14, \mathrm{HP} \beta \mathrm{CD}$ were found to be,-340.77,-440.51,-494.69,-554.7,-597.59 and in case of MBCD,-461.65,-582.47,-661.28,-721.97,770.41. The $\Delta \mathrm{Gtr}^{\circ}$ values were all negative for CDs at various concentration, giving idea about the spontaneous nature of FBX solubilisation, and it decreased with an increase in its concentration, indicating that the reaction became more favourable as the concentration of CDs increased. ${ }^{12}$ These values indicated that the system was releasing the energy upon complexation forming a ordered complexes respectively, implying highly stable physical state of all the complexes.

Particle size and zeta potential analysis. The particle size analysis found out of all complexes to be in micron range. The particle size of pure FBX was found to be $2.7333 \mu \mathrm{m}$. The particle size of the binary systems was, $1.0889 \mu \mathrm{m} 0.1901 \mu \mathrm{m}, 0.8227 \mu \mathrm{m}$ of $\beta C D, H P \beta C D$ and $M \beta C D$ complexes respectively. Using spray drying technology, the size of pure drug was significantly reduced in formulations. ${ }^{13}$ This has increased the specific surface area thereof enhancement of dissolution of FBX particles. ${ }^{14}$ The uniformity of the particle size can be examined by the determination of the polydispersity index (PI) which was found to be less than 1 in case of HP $\beta C D$ and $\mathrm{M} \beta C D$ systems whereas $\beta C D$ system showed the PI approaching the value 1 as shown in table 3 . All the systems were subjected to zeta potential analysis and values were found to be as shown in table 3 . The values of zeta potential for $\beta C D$ and $M \beta C D$ systems were found to be approaching towards the stability values whereas the HP $\beta C D$ system showed slight increase in the stability than that of the FBX. ${ }^{15}$

X-ray powder diffractometry (XRPD). The physical state of pure drug and all binary systems can be determined by evaluating the XRPD patterns as shown in the figure 4 . The diffractogram of FBX (Figure 4A) exhibited $2 \theta$ values at 11.30 (1020), 15.48 (522), 17.04 (466), 24.60 (819), 25.33 (839) indicative of its crystalline nature. In case of $\mathrm{HP} \beta \mathrm{CD}$ and $\mathrm{M} \beta \mathrm{CD}$ (Figure 4B, 4F respectively) a typical halo-pattern unveiling its amorphous character appeared whereas $\beta C D$ (Figure 4D) showed the $2 \theta$ values at 10.67 (1750), 12.39 (1554), 15.38 (734),18.71 (1027), 22.65 (1051) indicating its crystalline nature. The intense peaks in the diffraction pattern of FBX and CDs (Figure 4C, 4E, 4G) were 
completely diffused in the binary complexes providing the information of significant reduction in the crystallinity contributing to its solubility and dissolution enhancement. ${ }^{14}$

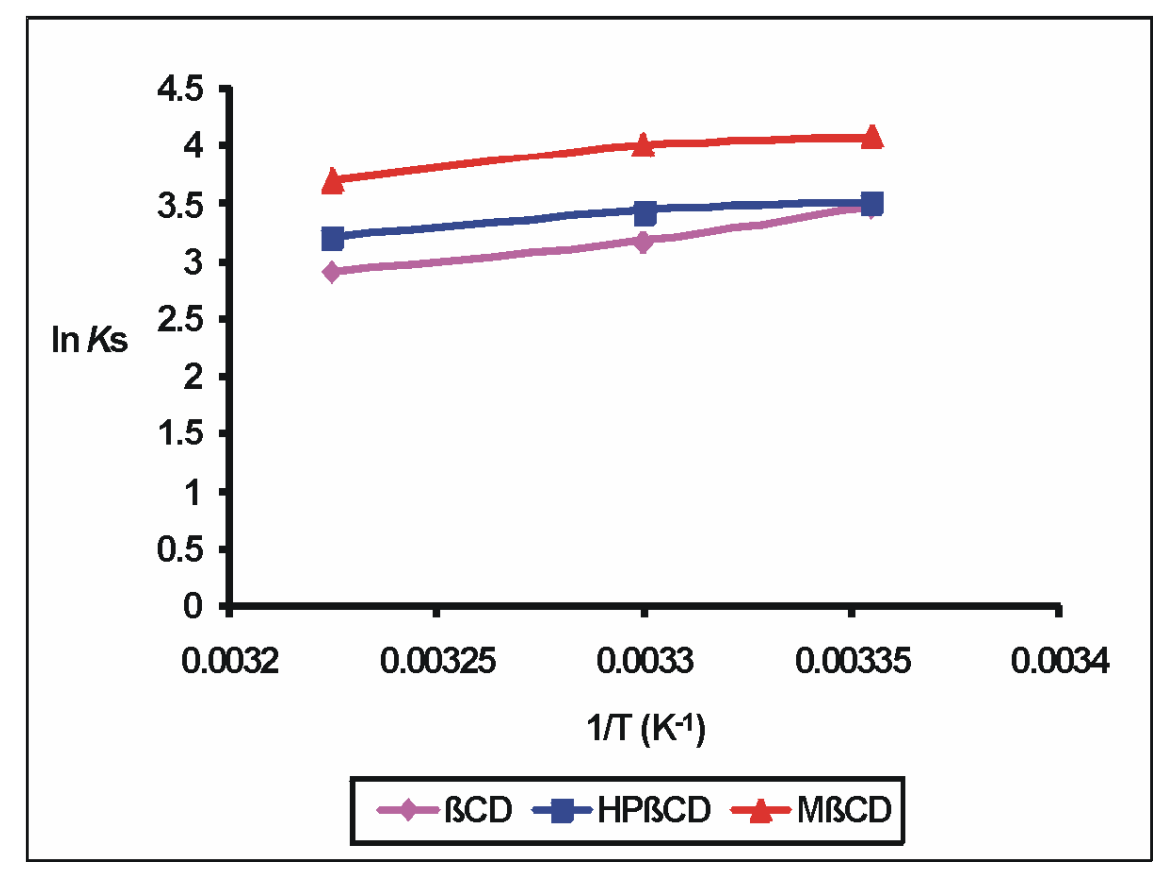

Figure 3. Van't Hoff plots (ln $K$ vs 1/T) for FBX: $\beta C D$, FBX:HP $\beta C D$, FBX:M $\beta C D$ inclusion complexes, determined by solubility diagrams experiments. FBX:Febuxostat; $\beta C D$ : $\beta$-cyclodextrin; HP $\beta C D$ : Hydroxy propyl $\beta$-cyclodextrin; M $\beta C D$ :Methyl $\beta$-cyclodextrin.

Differential scanning calorimetry (DSC). DSC technique has been widely used to study the interaction between host and guest molecules. When the drug is complexed in $\mathrm{CD}$ cavity, its melting points usually shift to different temperatures or disappears. ${ }^{16-18}$

DSC pattern of FBX and all systems are shown in Figure 5. DSC thermogram of FBX showed sharp melting point endotherm at $195.36^{\circ} \mathrm{C}$ (Figure 5A), while thermogram of $\mathrm{HP} \beta \mathrm{CD}$ did not exhibit any melting endotherm (Figure 5B) indicating its amorphous nature. The broad endothermic peaks shown by $\beta C D$ at $96.41^{\circ} \mathrm{C}$ (Figure 5D), indicated the crystalline phase that was diffused in its binary complex. M $\beta C D$ exhibited the endothermic peak at $73.67{ }^{\circ} \mathrm{C}$ (Figure 5F), indicative of water loss due to dehydration process. ${ }^{19,20}$ The binary complexes
(Figure 5C, 5E, 5G) showed the disappearance of the broad endotherms of pure FBX confirming its entrapment in $\mathrm{CD}$ cavities replacing the water molecules. These results theorize the presence of physical interaction between the FBX and CDs forming stable inclusion complex.

Fourier transformation infrared spectroscopy (FTIR). The various possible interactions between the drug and the CDs were studied by ATR-IR spectroscopy. The IR spectras of all the systems are shown in Figure 6.

The principle absorption peaks of FBX (Figure 6A) were observed at $2227 \mathrm{~cm}^{-1}$ ( $\mathrm{C} \equiv \mathrm{N}$ stretch), 2964 $\mathrm{cm}^{-1}$ (C-H stretch, aliphatic/ asymmetric), $2876.91 \mathrm{~cm}^{-}$ ${ }^{1}$ (C-H stretch, aliphatic symmetric), $1424.72 \mathrm{~cm}^{-1}$ $(\mathrm{C}=\mathrm{N}), \quad 1513.45 \mathrm{~cm}^{-1} \quad(\mathrm{C}=\mathrm{C}$ stretch, aromatic $)$, $725.12 \mathrm{~cm}^{-1}\left(\mathrm{CH}_{2}\right.$-stretch), $1288.46 \mathrm{~cm}^{-1}$ (C-N stretch) 


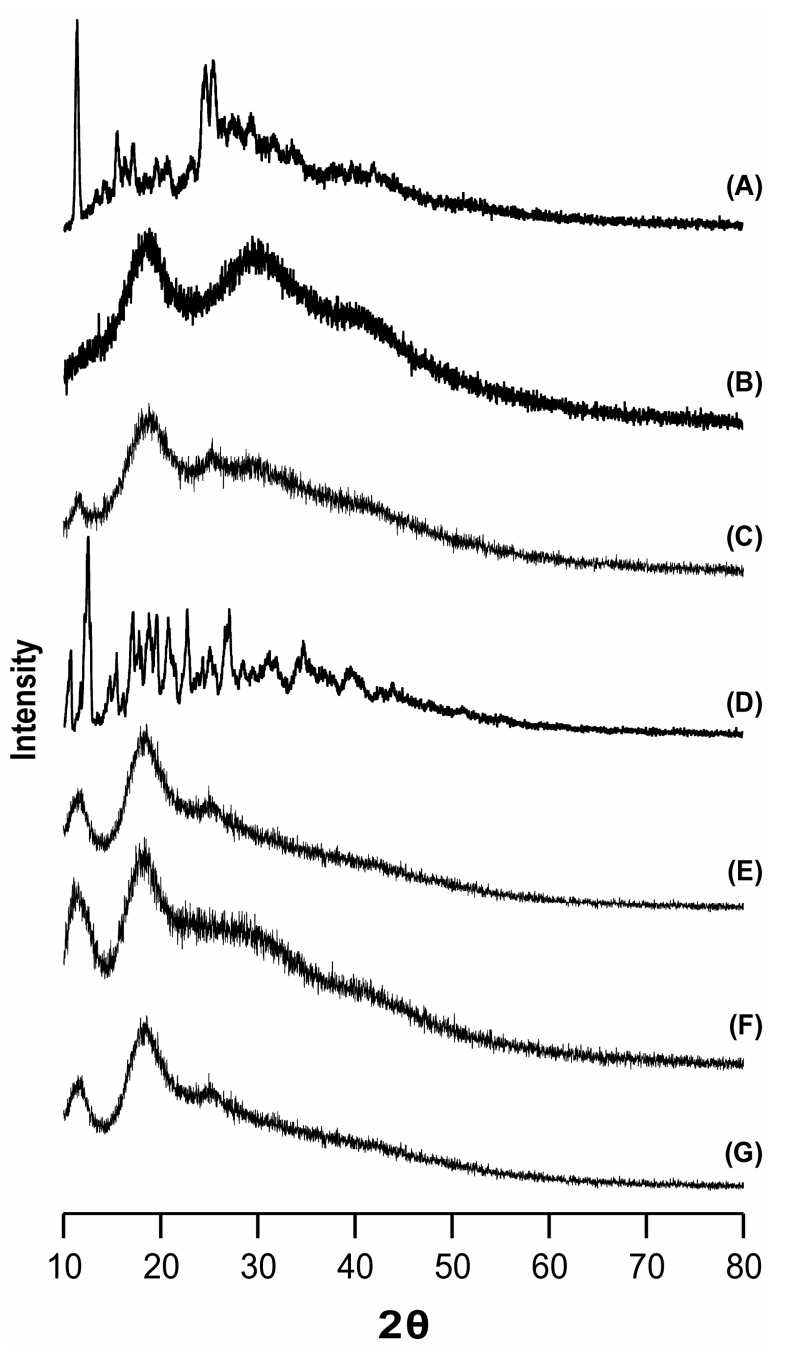

Figure 4. XRPD patterns of FBX (A), HPßCD (B), HPßCD complex (C), $\beta C D(D), \beta C D$ complex (E), $\mathrm{M} \beta C D(F), M \beta C D$ complex (G). FBX: Febuxostat; $\beta C D$ : $\beta$-cyclodextrin; HP $\beta C D$ : Hydroxy propyl $\beta$-cyclodextrin; M $\beta C D$ : Methyl $\beta-$ cyclodextrin.

and $3534.29 \mathrm{~cm}^{-1}(\mathrm{O}-\mathrm{H}$ stretch $)$. Figure $6 \mathrm{~B}$ shows absorption bands of $\mathrm{HP} \beta C D$ at $3379.88 \mathrm{~cm}^{-1}(\mathrm{O}-\mathrm{H}$ stretch), $1022.17 \mathrm{~cm}^{-1}$ (C-O-C stretch), $1655.32 \mathrm{~cm}^{-1}$ ( $\mathrm{H}-\mathrm{OH}$ bending). Figure $6 \mathrm{D}$ displays spectra of $\beta \mathrm{CD}$ at $3405.10 \mathrm{~cm}^{-1}$ (O-H stretch), $2945.01 \mathrm{~cm}^{-1}$ (C-H stretch, symmetric), $1645.63 \mathrm{~cm}^{-1}$ (H-OH bending), $1030.45 \mathrm{~cm}^{-1}$ (C-O-C stretch). In the spectra of $\mathrm{M} \beta \mathrm{CD}$ (Figure 6F), absorption peaks appered at $3362.41 \mathrm{~cm}^{-1}$ (O-H stretch), $1010.32 \mathrm{~cm}^{-1}$ (C-O-C), $2943.88 \mathrm{~cm}^{-1}$ (C-H stretch), $1637.28 \mathrm{~cm}^{-1}$ (H-O-H),

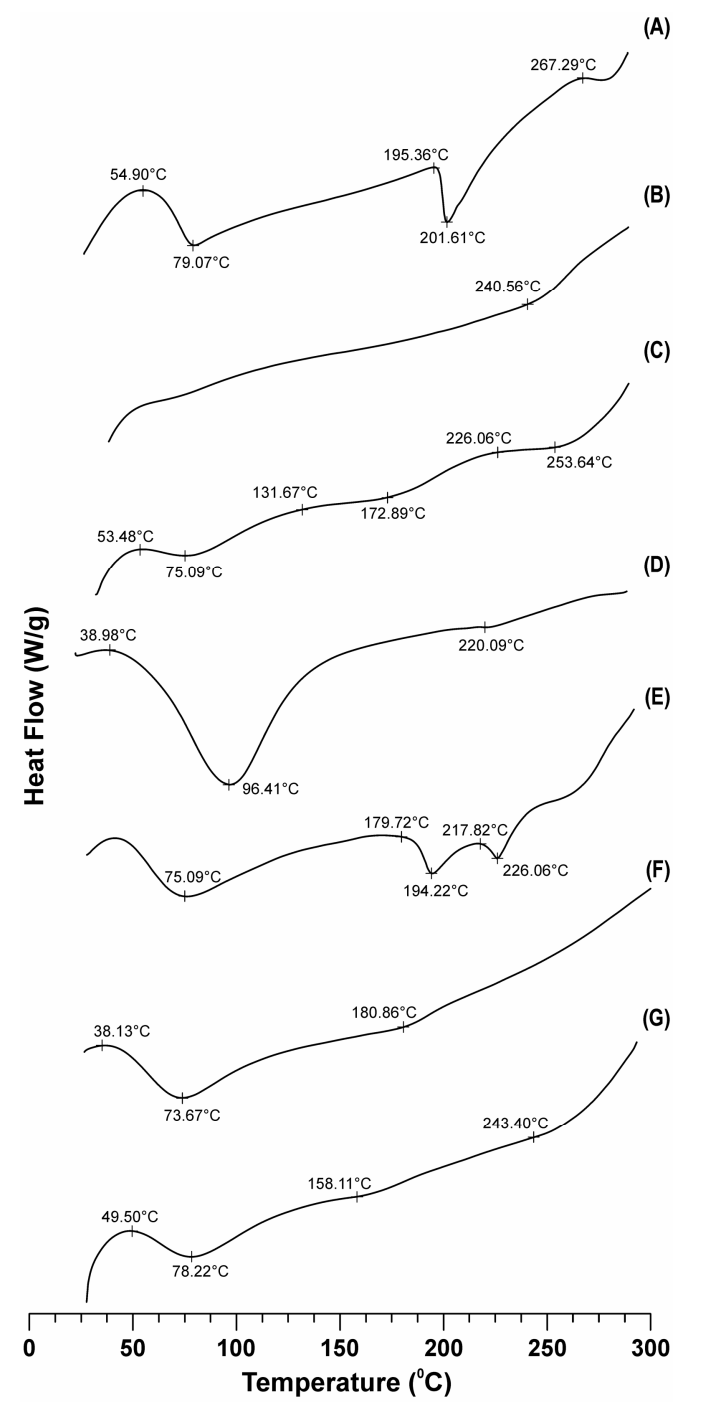

Figure 5. DSC thermograms of FBX (A), HP $\beta C D$ (B), HP $\beta C D$ complex (C), $\beta \mathrm{CD}(\mathrm{D}), \beta \mathrm{CD}$ complex (E), $\mathrm{M} \beta \mathrm{CD}(\mathrm{F}), \mathrm{M} \beta \mathrm{CD}$ complex (G). FBX: Febuxostat; $\beta C D$ : $\beta$-cyclodextrin; HP $\beta C D$ : Hydroxy propyl $\beta$-cyclodextrin; M $\beta C D$ : Methyl $\beta$ cyclodextrin.

$2943.88 \mathrm{~cm}^{-1}$ (C-H aliphatic). In case of all the binary systems (Figure 6C, 6E, 6G) the prominent peaks of FBX and the CDs were modified (frequency shift / attenuation/ broadening). The peaks observed in the formulation were found to be smooth and showed no appearance of any new peak suggesting existence of only physical interaction between host and guest. ${ }^{21}$

Scanning electron microscopy (SEM). SEM was used to investigate the microscopic surface and morphological characteristics of pure drug and 
complexes as shown in figure 7. FBX was characterized by the presence of uneven and elongated particles. The microphotographs of spray dried inclusion complexes showed the characteristic morphology as spherical pieces of amorphous aggregates and the original morphologies of pure FBX diminished. These microphotographs suggested

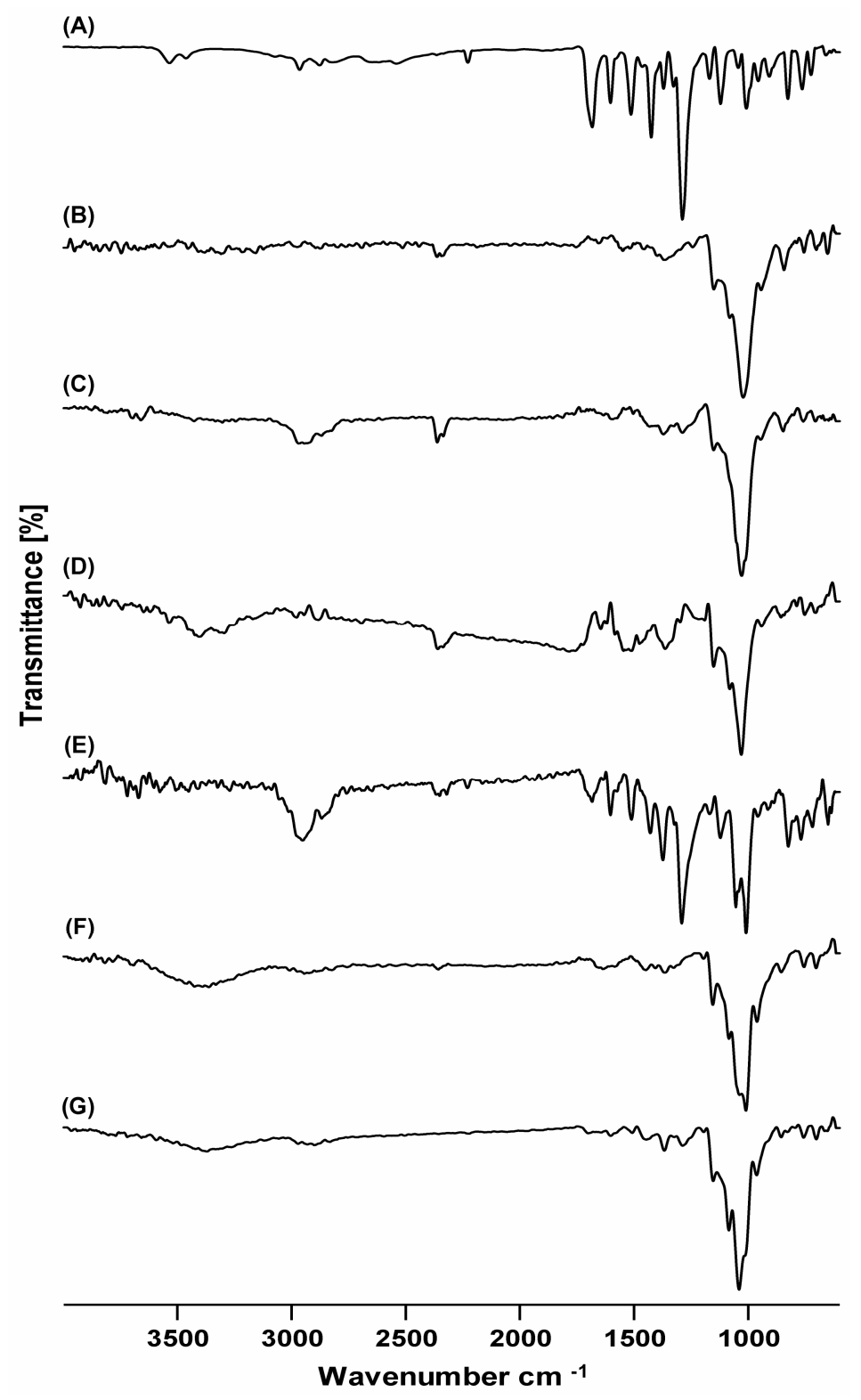

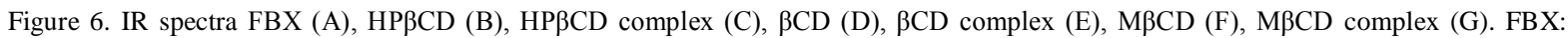
Febuxostat; $\beta C D$ : $\beta$-cyclodextrin; HP $\beta C D$ : Hydroxy propyl $\beta$-cyclodextrin; $M \beta C D$ : Methyl $\beta$-cyclodextrin.

the formation of complexes of FBX with hydrophilic $\beta C D, H P \beta C D$ and $M \beta C D$ in the solid state. Thus, altered particle shape, amorphous aggregates and close contact between hydrophilic CD in complexes might be responsible for improved physicochemical properties of FBX. Further spray drying technology had contributed for amorphous natured complexes resulting improved drug release from the complexes. ${ }^{14}$ 
Percentage drug content and saturation solubility studies. The percentage drug content of FBX- $\beta C D, \quad F B X-H P \beta C D$ and FBX-M $\beta C D$ microcomplexes were found to be $71.35 \pm 0.65$, $99.03 \pm 0.24$ and $99.99 \pm 1.01 \mathrm{w} / \mathrm{w}$ respectively.

The saturation solubility of pure FBX, FBX$\beta C D$, FBX-HP $\beta C D$ and FBX-M $\beta C D$ complexes observed to be $14.9 \pm 0.0200 \mu \mathrm{g} / \mathrm{ml}, 21.693 \pm$ $0.03512 \mu \mathrm{g} / \mathrm{ml}, 304.7 \pm 0.04163 \mu \mathrm{g} / \mathrm{ml}$ and $1200.3 \pm$
$0.25 \mu \mathrm{g} / \mathrm{ml}$, respectively. The spray dried $\beta C D$, HP $\beta C D, M \beta C D$ systems showed 1.451, 20.424 and 80.449 fold increase in solubility as compared to pure FBX alone. The enhancement in solubility of FBX from complexes was associated to amorphisation, wetting property and hydrophilicity of CDs, improved complexation efficiency and formation of stable inclusion complexes. ${ }^{14}$

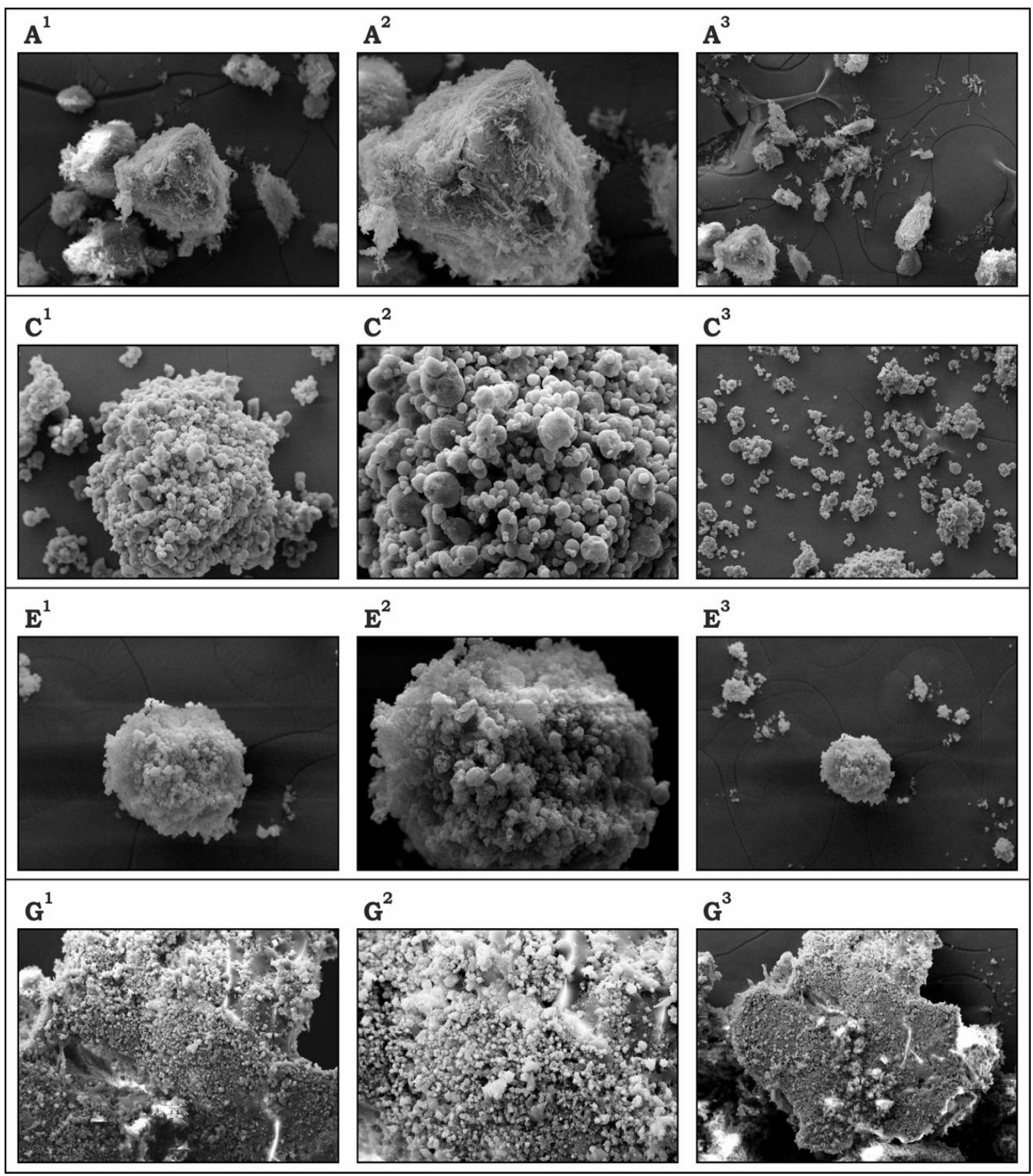

Figure 7. SEM of FBX (A), HP $\beta C D$ complex (C), $\beta C D$ complex (E), M $\beta C D$ complex (G) ${ }^{1} 1 \mathrm{kx}$ magnification; ${ }^{2} 2 \mathrm{kx}$ magnification; ${ }^{3} 500 \mathrm{x}$ magnification. FBX: Febuxostat; $\beta C D$ : $\beta$-cyclodextrin; HP $\beta C D$ : Hydroxy propyl $\beta$-cyclodextrin; M $\beta C D$ : Methyl $\beta$-cyclodextrin. 


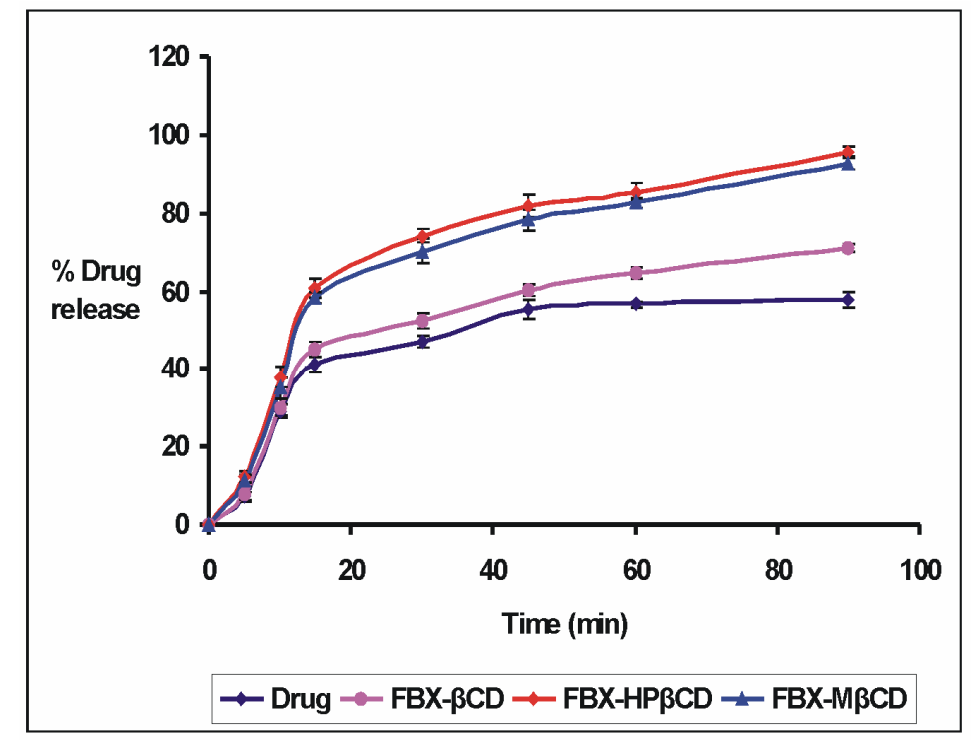

Figure 8. The dissolution Profile of FBX, FBX- $\beta C D$, FBX-HP $\beta C D$, FBX-M $\beta C D$ complexes at $37 \pm 0.5^{\circ} \mathrm{C}$ in phosphate buffer ( $\mathrm{pH} 7.4$ ). FBX: Febuxostat; $\beta C D$ : $\beta$-cyclodextrin; HP $\beta C D$ : Hydroxy propyl $\beta$-cyclodextrin; M $\beta C D$ : Methyl $\beta$-cyclodextrin.

In vitro drug release. The FBX release profile from respective complexes is presented in figure 8. The release rate profiles were given as the percentage of drug dissolved (vs.) time. The values of $\%$ drug dissolved in 90 mins $\left(\mathrm{DP}_{90}\right)$ were statistically evaluated. From the results obtained, an improvement in dissolution profile was seen for the binary complexes in comparison to the pure drug. Within the complexes, $\mathrm{HP} \beta C D$ and $\mathrm{M} \beta C D$ systems demonstrated the highest drug dissolution in $90 \mathrm{~min}$ than that of $\beta C D$ which might be attributed to amorphous natute of $\mathrm{HP} \beta C D$ and $\mathrm{M} \beta \mathrm{CD}$ over crystallinity of $\beta C D$. However, no significant difference was observed between dissolution profiles of the $\mathrm{HP} \beta C D$ and $\mathrm{M} \beta C D$ complexes. The improvement in dissolution of the complexes was attributed to greater hydrophilicity, wetting property, increased contact amoung the drug and the CDs due to use of spray drying technology and ability to form stable inclusion complexes. ${ }^{22-25}$

Determination of partition coefficient $(\log P)$. The $\log P$ values of FBX, FBX- $\beta C D$, FBX-HP $\beta C D$ and FBX-M $\beta C D$ complexes were found to be $3.953 \pm$ $0.056,2.03 \pm 0.020,1.533 \pm 0.025,1.666 \pm 0.025$, respectively at $25 \pm 2^{\circ} \mathrm{C}$. The reduced $\log P$ values indicated enhancement in hydrophilicity of binary complexes in correlation to that of the FBX..$^{5}$ The use of modified CDs and amorphisation by spray drying resulted in more promising physiochemical properties of FBX.

\section{CONCLUSION}

The present studies revealed that FBX microcomplexes with parent and modified CDs were successfully formulated using spray drying technology that aided in an improvement of physicochemical properties in comparison to the drug alone. The thermodynamic specifications accomplished from solubility data at different temperatures was contributive in revealing complex formation between the CDs and FBX which was enthalpy driven exothermic process and spontaneous in nature. It could be concluded that the use of modified CDs over parent $\mathrm{CD}$ has offered remarkable advantage towards higher complexation efficiencies as well as dissolution profile due to formation of amorphous of complexes. The enhancement in solubility and dissolution profile of FBX was comprehensively attributed to inclusion complexation, amorphization and reduction in particle size attained using the spray drying technology. 


\section{ACKNOWLEDGEMENTS}

The authors are thankful to Shivaji University, Kolhapur,Maharashtra, India for providing the analytical facilities to perform the characterization studies. The authors are thankful to INDOCO Remedies Ltd.,Waluj, and Gangwal Chemicals, Mumbai, India for providing drug sample and CDs respectively, for the research work. Authors are also grateful to TCI Chemicals, Mumbai, India for providing $\mathrm{M} \beta \mathrm{CD}$ sample. The authors are thankful to the Principal, Government College of Pharmacy, Karad, Maharashtra, India for providing necessary laboratory facilities to carry out the research work. This research work has not been supported by any financial assistance.

\section{REFERENCES}

1. Loftson, T. and Brewster, M. 1996. Pharmaceutical applications of cyclodextrins: Drug solubilisation and stabilization. J. Pharm. Sci. 85, 1017-1025.

2. Loftsson, T., Jarho, P., Masson, M. and Jarvinen, T. 2005. Cyclodextrins in drug delivery. Expert Opin. Drug. Deliv. 2, $335-351$.

3. Aleem, O., Kuchekar, B. and Pore, Y. 2008. Effect of $\beta$ cyclodextrin and hydroxyl propyl- $\beta$-cyclodextrin complexation on physicochemical properties and antimicrobial activity of cefdinir. J. Pharm. Biomed. Anal. 47, 535-540.

4. Udrescu, L., Sbarcea, L. and Fulias, A. 2014. Physicochemical characterization of zofenopril inclusion complex with hydroxypropyl- $\beta$-cyclodextrin. J. Serb. Chem. Soc.79, 1-20.

5. Jadhav, P. and Pore, Y. 2016. Physiochemical, thermodynamic and analytical studies on binary and ternary inclusion complexes of bosentan with hydroxypropyl- $\beta$ cyclodextrin. Bull. Fac. Pharm. Cairo Univ. 55, 147-154.

6. Onyeji, C., Omoruyi, S. and Oladimeji, F. 2009. Physicochemical characteristaion and dissolution properties of binary systems of pyrimethamine and 2-hydroxypropyl- $\beta$ cyclodextrin. Afr. J. Biotechnol. 8, 1651-1659.

7. Takano, Y., Hase-Aoki, K. and Horiuchi, H. 2005. Selectivity of febuxostat, a novel non-purine inhibitor of xanthine oxidase/xanthine dehydrogenase. Life Sci. 76, 18351847.

8. Kuchekar, B., Divekar, B., Jagdale, S. and Gonjari, I. 2013. Solubility enhancement and formulation of rapid disintegrating tablet of febuxostat cyclodextrin complex. JPR Solutions. 1, 168-175.
9. Dass, R., Jaiswal, S. and Gupta, G. 2014. Formulation and evaluation of febuxostat fast disintegrating tablet. Indo Am. J. Pharm. Res. 4, 2928-2936.

10. Higuchi, T. and Connors, K.A. 1965. Phase-solubility techniques. Adv. Anal. Chem. Inst. 4, 117-212.

11. Davis, M. E. and Brewster, M. E. 2004. Cyclodextrin-based pharmaceutics. Past, present and future. Nat. Rev. Drug Discov. 3, 1023-1035.

12. Patel, R.P., Patel, D.J., Bhimani, D.B. and Patel, J.K. 2008. Physicochemical characterization and dissolution study of solid dispersions of furosemide with polyethylene glycol 6000 a polyvinyl pyrrolidone K30. Dissolut. Technol. 15, $17-25$.

13. Shoyele, S.A. and Cawthorne, S. 2016. Particle engineering techniques for inhales biopharmaceuticals. Adv. Drug Deliv. Rev. 58, 1009-1029.

14. Shah, M., Pore, Y., Dhawale, S.. Burade, K. and Kuchekar, B. 2013. Physiochemical characterization of spray dried ternary micro-complexes of cefuroxime axetil with hydroxyl$\beta$-cyclodextrin. J. Incl. Phenom. Macrocycl. Chem. 76, 391401.

15. Doiphode, D., Gaikwad, S., Pore, Y., Kuchekar, B. and Late, S. 2008. Effect of $\beta$-cyclodextrin complexation on physicochemical properties of zaleplon. J. Incl. Phenom. Macrocycl. Chem. 62, 43-50.

16. Jadhav, P., Petkar, B., Pore, Y., Kulkarni, A. and Burade, K. 2013. Physicochemical and molecular modeling studies of cefixime-L-arginine-cyclodextrin ternary inclusion compounds. Carbohydr. Polym. 98, 1317-1325.

17. Bora, D., Borude, P. and Bhise, K. 2008. Taste masking by spray-drying technique. AAPS Pharm. Sci. Tech. 9, 11591164.

18. Hassan, M.A., Suleiman, M.S. and Najib, N.M. 1990. Improvement of the in vitro dissolution characteristics of famotidine by inclusion in $\beta$-cyclodextrin. Int. J. Pharm. 58, 19-24.

19. Gajare, P., Patil, C., Kalyane, N. and Pore, Y. 2009. Effect of hydrophilic polymer on pioglitazone complexation with hydroxyl propyl $\beta$-cyclodextrin. Dig. J. Nanomater. Biostruct. 4, 891-897.

20. Sinha, V. R., Anitha, R., Ghosh, S., Nnda, A. and Kumaria, R. 2005. Complexation of celecoxib with $\beta$-cyclodextrin characterization of the interaction in solution and in solid state. J. Pharm. Sci. 94, 676-687.

21. Khade, S., Pore, Y. 2016. Formulation and evaluation of neusilin US2 adsorbed amorphous solid selfmicroemulsifying delivery system of atorvastatin calcium. Asian J. Pharm. Clin. Res. 9, 93-100. 
22. Sapte, S. and Pore, Y. 2016. Inclusion complexes of cefuroxime axetil with $\beta$-cyclodextrin: Physiocochemical characterization, molecular modeling and effect of L-arginine on complexation. J. Pharm. Anal. 6, 300-306.

23. Elkordy, A., Essa, E. and Faheem, A. 2009. Applications of spray drying and spray con-gealing to improve poorly water soluble drug dissolution. In Poster presentationat the 22nd annual conference of American Association of Pharmaceutical Scientists (AAPS).
24. Takeuchi, H., Nagira, S., Yamamoto, H. and Kawashima, Y. 2004. Solid dispersion particles of tolbutamide prepared with fine silica particles by the spray-drying method. Powder Technol. 141, 187-195.

25. Lin, S. and Kao, Y. 1989. Solid particulates of drug- $\beta$ cyclodextrin inclusion complexes directly prepared by spraydrying technique. Int. J. Pharm. 56, 249-259. 